\title{
Examination of the Quantitative Relationship between Vegetation Canopy Height and LAI
}

\author{
Yongwei Yuan, ${ }^{1}$ Xinsheng Wang, ${ }^{1}$ Fang Yin, ${ }^{2,3}$ and Jinyan Zhan ${ }^{4}$ \\ ${ }^{1}$ Faculty of Resources and Environmental Science, Hubei University, Hubei, Wuhan 430062, China \\ ${ }^{2}$ Institute of Geographic Sciences and Natural Resources Research, Chinese Academy of Sciences, Beijing 100101, China \\ ${ }^{3}$ Center for Chinese Agricultural Policy, Chinese Academy of Sciences, Beijing 100101, China \\ ${ }^{4}$ State Key Laboratory of Water Environment Simulation, School of Environment, Beijing Normal University, Beijing 100875, China
}

Correspondence should be addressed to Jinyan Zhan; zhanjy@bnu.edu.cn

Received 16 July 2013; Accepted 1 October 2013

Academic Editor: Xiangzheng Deng

Copyright (C) 2013 Yongwei Yuan et al. This is an open access article distributed under the Creative Commons Attribution License, which permits unrestricted use, distribution, and reproduction in any medium, provided the original work is properly cited.

\begin{abstract}
Accurate estimation of vegetation biophysical variables such as the vegetation canopy height $(H)$ is of great importance to the applications of the land surface models. It is difficult to obtain the data of $H$ at the regional scale or larger scale, but the remote sensing provides the most useful and most effective method. The leaf area index (LAI) is closely related to the $H$, and we analyzed its relationship with the correlation analysis based on the dataset at 86 site-years of field measurements from sites worldwide in this study. The result indicates that there is significant positive exponent correlation between these two parameters and the change of LAI would exert great impacts on $H$. The higher the LAI is, the higher the $H$ is, and vice versa. Besides, the coefficients of different land cover types are very heterogeneous, and LAI of the needleleaf forest shows strong correlation with $H$, while that of the cropland shows weak correlation with $H$. The results may provide certain reference information for the extraction of the data of $H$ at the regional scale with the remote sensing data.
\end{abstract}

\section{Introduction}

The vegetation plays an important role in the transfer of heat, momentum, and substance in the Earth system [1], and the accurate estimation of vegetation biophysical variables is of great importance to the agricultural, ecological, and meteorological applications [2]. The structural factors of vegetation, such as the leaf area index (LAI) and vegetation canopy height $(H)$, have direct influence on the surface albedo, surface roughness, surface temperature, surface moisture, and so forth, all of which are important input parameters of the models such as land surface models (LSM), regional climate model (RCM), and global climate model (GCM) [3]. Therefore, the data accuracy of the vegetation density and height may have great impacts on the uncertainties in the simulation results with these models.

Both LAI and $H$ are important vegetation physiological parameters that have close relationship with the ecological, hydrological, and climatic models. $H$ is an important ecological metric that can provide essential information to scientists interested in understanding or modeling a wide range of atmospheric, hydrological, biophysical, and ecological processes in the forest and shrubland [4], while LAI is also one of the most important vegetation parameters and land property indices that serve as a primary controlling factor of the exchange of energy, water, and carbon fluxes between the terrestrial ecosystems and the atmosphere [5-8]. As the primary attribute of the vertical structure, $H$ affects the boundary layer meteorology and microclimate [9]. Besides, $H$ plays a very important role in the interface between atmosphere and land surface in many ways. For example, since the physical processes generally change at the $H$, the quantities of physical parameters (e.g., wind speed, temperature and concentration of $\mathrm{CO}_{2}$ ) above the ground surface are often normalized at the $H$, and sometimes these physical parameters are also normalized with their values at the $H$ [10] . In addition, some studies demonstrated that $H$ also plays an important role in influencing the biogeochemical properties 
of the land system. For example, Desai et al. showed that $H$ had a strong correlation with $\mathrm{CO}_{2}$ fluxes [11]. $\mathrm{H}$ is a fundamental variable in allometric equations that estimate the forest biomass and productivity $[12,13]$. Therefore, $H$ is a very important parameter in many research fields; however, the current land cover and vegetation classifications usually provide little and even no information about $H$ beyond the most basic structural vegetation distinctions [4].

Land surface models such as CESM, SEBAL, and METRIC $[14,15]$ can calculate the surface fluxes as a function of the aerodynamic resistance for the heat transfer, which is a function of aerodynamic roughness length $z 0(\mathrm{~m})$. In these models zero-plane displacement $d(\mathrm{~m})$ and $z 0$ may be derived from a variety of canopy structure inputs. At the most basic resolution, $d$ and $z 0$ are simple linear functions of site-level $H$, typically $d \approx 0.66 H$ and $z 0 \approx 0.10 H[16,17]$. Some studies took $d$ and $z 0$ as a proportion of $h$ [18]. This increases the uncertainties of the simulation results. Pitman (1994) showed that a $30 \%$ error in the estimation of $z 0$ within LSM could lead to a $15 \%$ error in estimation of the sensible heat flux over forested environments [19]. Besides, parameters such as $d$ and $z 0[20,21]$ are often normalized by $H$ for intersite comparison studies. Both $d$ and $z 0$ are primarily dependent on $H$, though the normalized values $d / H$ and $z 0 / H$ are known to vary with the canopy density and/or LAI [20-22].

Some researchers have found that there is a relatively high correlation between the $H$ estimates from NASA's active laser vegetation imaging sensor (LVIS) and maximum $H$ values of the Howland Forest measured in the field [23, 24]. However, there is some limitation in the spatial extent of the data obtained from the airborne LIDAR sensors such as LVIS [25], and it is necessary to develop some efficient methods to estimate $H$ using optical remote sensing [26]. Unfortunately, there have been no mature approaches yet. Currently, the light detection and ranging (LIDAR) data can provide detailed information about the forest canopy height in the vertical plane $[25,27]$. For example, the current remote sensing data, for example, the Landsat data, can provide useful structural information in the horizontal plane, but these data are relatively insensitive to the $H$. It has become a popular and effective method to extract the $H$ based on the remote sensing data at the regional scale [6], and it has also become an important scientific issue to analyze the relation between $H$ and other relevant parameters of vegetation which can be easily accessed by remote sensing.

In terms of the relationship between the vegetation characteristics, other researches have evaluated the relationships between vegetation indices, canopy structure, physiology, and biomass [28, 29]. Besides, some previous researches have reported that there is close relationship between LAI and the land cover type [30]. However, there are few studies about the direct physical relationship between them. In this study, we have assumed that there is certain linear relationship between them and analyzed this relationship with the regression between $H$ and LAI on the basis of observation data collected from 86 sites covering various vegetated surfaces. The result of this study may provide certain reference value for indirect extraction of $H$ at the regional and global scale.

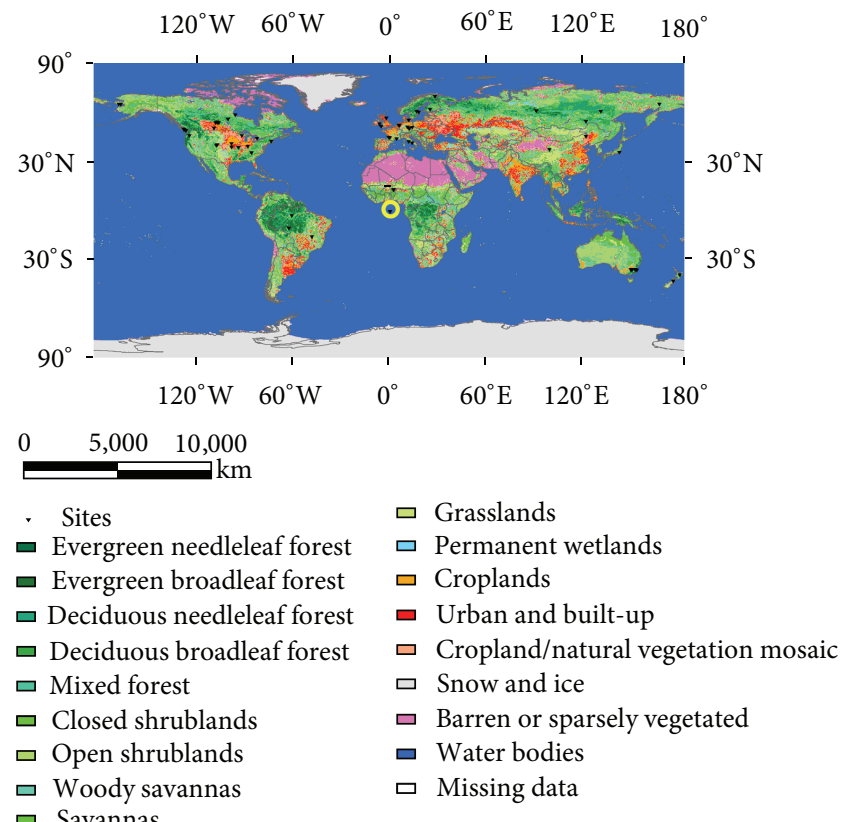

FIGURE 1: Spatial distribution of sites.

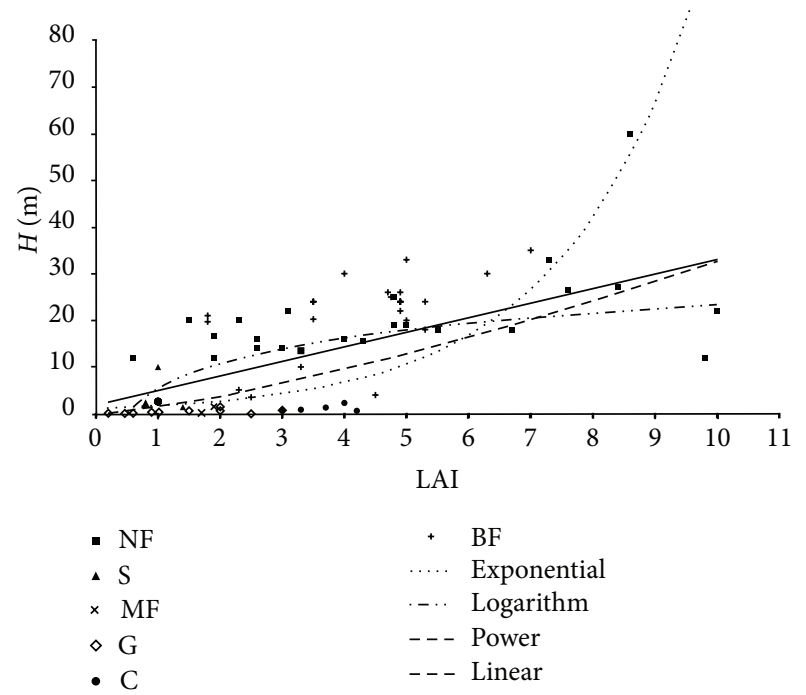

FIGURE 2: Result of fitting curve of $H$ and LAI BF (broadleaf forest), NF (needleleaf forest), C (croplands), G (grasslands), S (savannas), and (MF) shrublands.

\section{Data}

The dataset used in this study mainly includes the data of $H$ and LAI, both of which are considered as important parameters of the land surface characteristics in most sites [31]. In this study, we have collected and sorted out data of the vegetation and structure parameters at 86 site-years of field measurements from sites worldwide. The original vegetation cover data were sorted into 17 types [32] according to vegetation/land cover classification system standard by International Geosphere-Biosphere Program (IGBP) [33]. Figure 1 shows the spatial distribution of these sites. In 


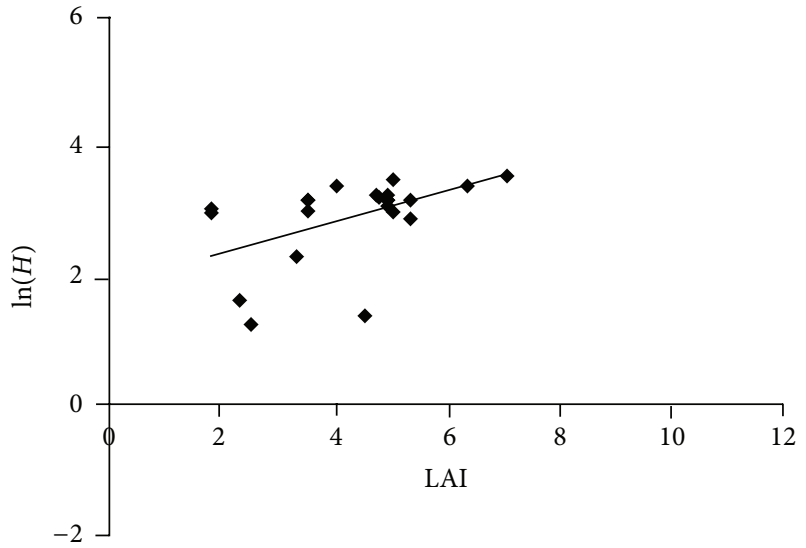

(a)

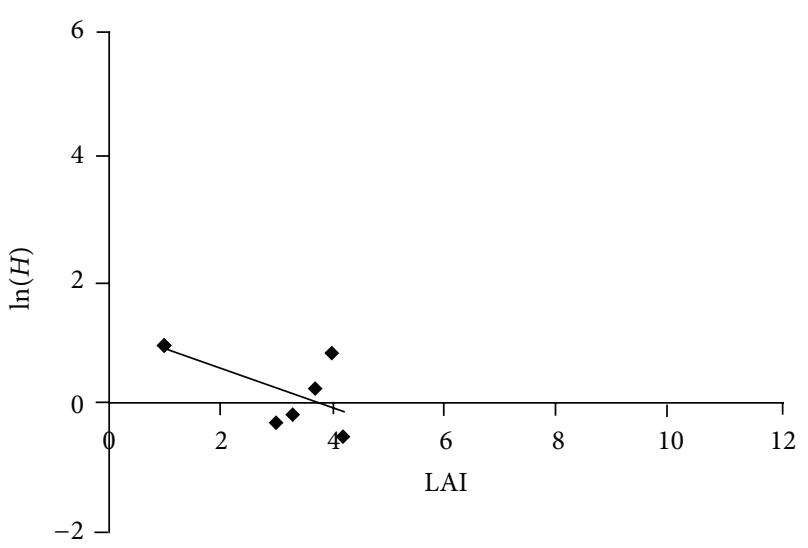

(c)

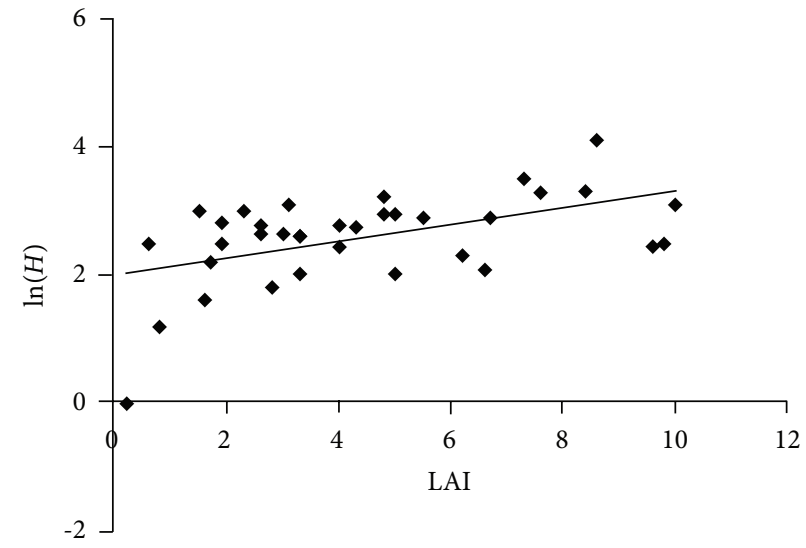

(b)

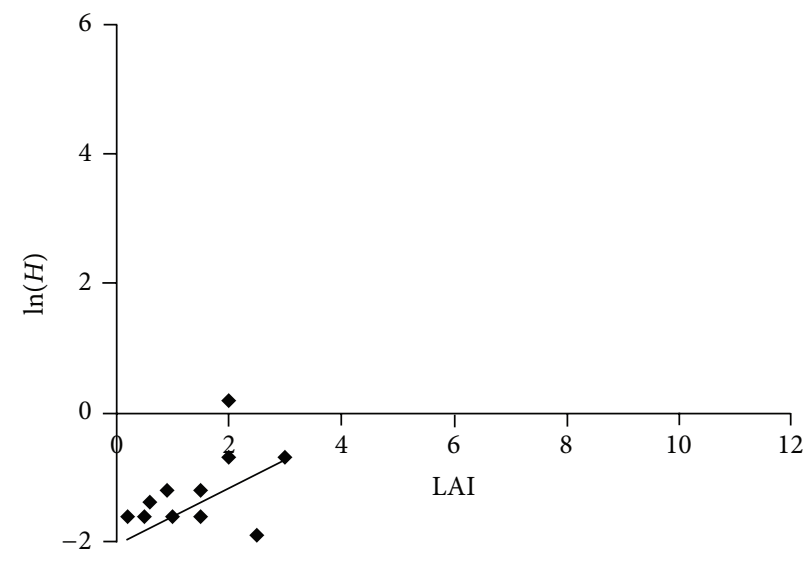

(d)

Figure 3: Scatter plots between $\ln (H)$ and LAI, (a) broadleaf forest, (b) needleleaf forest, (c) croplands, and (d) grasslands.

Figure 1, the five site-years in the yellow circle, which do not have the coordinate information, are from the second version (Version 2) database of the Global Land Cover Characteristics.

In this study, the dataset of $H$ and LAI comes from two data sources. The first dataset is the dataset of net carbon dioxide and water fluxes of global terrestrial ecosystems, 1969-1998. The Oak Ridge National Laboratory Distributed Active Archive Center (ORNL DAAC) for Biogeochemistry Dynamics organized and formatted these data for long-term archive. The data file of 133 study sites includes 110 micrometeorological studies and 23 enclosure studies. The type of study (micrometeorological or enclosure) and classification of the ecosystem given by Buchmann were added to each entry. Data used in this paper is measurement site locations and several physical and biophysical characteristics (e.g., $H$, LAI, and stand age) and finally sorted out valid data record 53. The second dataset comes from the research results of Cho et al. (2012) [34]. The data is measured at the peak of the leaf biomass in the specified year for each site and categorized by the IGBP vegetation classification system. In this dataset, there are 33 records.

The dataset which contains information of latitude, longitude, LAI (maximum), and $H$ (maximum) in the sites was finally established. Descriptive statistics for the variables of this dataset are included in Table 1. For the analysis, we reclassified the original vegetation types into the types of the IGBP classification system. Then statistics of different types of record number were incorporated into NF (needleleaf forest), BF (broadleaf forest), C (croplands), G (grasslands), MF (shrublands), and savannas (Table 2). The main surface vegetation type of the site is grasslands, croplands, forests (deciduous broadleaf Forests, deciduous needleleaf forests, evergreen needleleaf forests, evergreen broadleaf forests, and open/closed shrublands), and savannas. Then the land cover classification system of vegetated surface was got after excluding nonvegetation surface types, including urban and built-up (13), snow and ice (15), water bodies (17), land cover classification types with nonsite distribution mixed forest (5), woody savannas (8), permanent wetlands (11), cropland/natural vegetation mosaic (14), and barren or sparsely vegetated (16).

\section{Results}

The correlation analysis between $H, \ln (H)$, LAI, and $\ln (\mathrm{LAI})$ was implemented one by one, and finally the correlation 
TABLE 1: Descriptive statistics of the dataset at 86 site-years of field measurements from sites worldwide.

\begin{tabular}{lccccc}
\hline Variable & Obs. & Mean & Std. dev. & Min & Max \\
\hline$H$ & 86 & 12.71 & 11.49 & 0.05 & 60 \\
LAI & 86 & 3.48 & 2.36 & 0.2 & 10 \\
Latitude & 81 & 33.12 & 32.08 & -42.2 & 69.47 \\
Longitude & 81 & -9.18 & 97.61 & -164.73 & 176 \\
\hline
\end{tabular}

TABLE 2: Sites statistical distribution in IGBP land cover classification system.

\begin{tabular}{|c|c|c|c|}
\hline Code & IGBP classification & Obs. & Merge sorting \\
\hline 1 & Evergreen needleleaf forest & 16 & NF \\
\hline 2 & Evergreen broadleaf forest & 2 & $\mathrm{BF}$ \\
\hline 3 & Deciduous needleleaf forest & 19 & NF \\
\hline 4 & Deciduous broadleaf forest & 21 & $\mathrm{BF}$ \\
\hline 5 & Mixed forest & - & - \\
\hline 6 & Closed shrublands & 1 & MF \\
\hline 7 & Open shrublands & 1 & MF \\
\hline 8 & Woody savannas & - & - \\
\hline 9 & Savannas & 4 & S \\
\hline 10 & Grasslands & 14 & G \\
\hline 11 & Permanent wetlands & - & - \\
\hline 12 & Croplands & 8 & $\mathrm{C}$ \\
\hline 14 & Cropland/natural vegetation mosaic & - & - \\
\hline 16 & Barren or sparsely vegetated & - & - \\
\hline
\end{tabular}

Note. The table excluded nonvegetation surface types which are urban and built-up (13), snow and ice (15), and water bodies (17). So “-” means that such land cover types do not exist.

TABLE 3: Correlation matrix of $H, \ln (H)$, LAI, and $\ln (\mathrm{LAI})$.

\begin{tabular}{lcccc}
\hline & \multicolumn{2}{c}{$H$} & \multicolumn{2}{c}{$\ln (H)$} \\
& Pearson value & $\begin{array}{c}\text { Significance } \\
\text { (bilateral) }\end{array}$ & Pearson value & $\begin{array}{c}\text { Significance } \\
\text { (bilateral) }\end{array}$ \\
\hline LAI & 0.641 & 0.000 & 0.609 & 0.000 \\
$\ln ($ LAI $)$ & 0.616 & 0.000 & 0.681 & 0.000 \\
\hline
\end{tabular}

matrix was obtained. The result indicated that the Pearson correlation value of LAI and vegetation height $(H)$ and $\ln (H)$ reached 0.64 and 0.616 , respectively, while there is a more sensitive correlation between $\ln (H)$ and LAI and $\ln (\mathrm{LAI})$ since their Person value was 0.609 and 0.681 , respectively.

The result shows that there is a positive correlation between all of $H, \ln (H)$, LAI, and $\ln (\mathrm{LAI})$ (Table 3 ). There is the most significant correlation between $\ln (H)$ and $\ln (\mathrm{LAI})$, which is significant at the $1 \%$ level of significance (bilateral), and their correlation coefficient is 0.681 . It is followed by that between $H$ and LAI, the correlation coefficient of which is 0.641 . The significance level of $\ln (H)$ and LAI is the weakest, and their correlation coefficient is 0.609 . By inquiring the critical value table of the correlation coefficient, it is found that the correlations between $H, \ln (H), \mathrm{LAI}$, and $\ln (\mathrm{LAI})$ are all significant at the $99 \%$ level of confidence.

The regression analysis of $H$ and LAI was implemented with the SPSS software, with $H$ being the dependent variable and LAI being the independent variable. The results are as follows: the summarized conditions of the regression model, the estimated values of parameters, the results of curve fitting of $H$ and LAI, and the final regression equations (Table 4, Figure 2).

The result indicated that these functions all reflected the relationship between $H$ and LAI to some degree. The result suggests that the result of curve fitting of $H$ and LAI with the power function is the most proper, which can effectively reflect the correlation between $H$ and LAI $\left(y=1.4915 x^{1.3396}\right.$, $\left.R^{2}=0.464\right)$. It is followed by the linear fitting $\left(R^{2}=0.411\right)$, while the result with the exponential function is the worst $\left(R^{2}=0.371\right)$.

Although the power function can reflect the correlation between $H$ and LAI best, it is found that the logarithmic function can better reflect the correlation between $H$ and LAI to some degree when the single or several land cover types are taken as the research object. So the logarithmic function has been used to analyze the correlation between $H$ and LAI with the combined land cover types as the research object in this study, including the land cover BF, NF, C, and G.

The results of the analysis with the logarithmic function are as follows. Figures 3(a), 3(b), 3(c), and 3(d) represents the scatter plots between $\ln (H)$ and LAI of the broadleaf forest, needleleaf forest, croplands, and grasslands, respectively. The solid lines represent the fitted line of the changing trend, the fitted equations, their fitting variances $\left(R^{2}\right)$, and significance level; see Table 5.

The result indicated that the changing trends of $H$ and LAI of broadleaf forest, needleleaf forest, and grasslands tend to converge; that is, they show a positive correlation on 
TABLE 4: Summarization of regression models and estimated values of parameters.

\begin{tabular}{|c|c|c|c|c|c|c|c|c|}
\hline \multirow{2}{*}{ Models } & \multicolumn{5}{|c|}{ Summarization of the model } & \multicolumn{2}{|c|}{ Estimated values of parameters } & \multirow{2}{*}{ Regression models } \\
\hline & $R^{2}$ & $F$ & df1 & $\mathrm{df} 2$ & Sig. & Constant & $b_{1}$ & \\
\hline Liner & 0.41 & 58.64 & 1 & 84 & 0.00 & 1.846 & 3.120 & $y=3.120 x+1.846$ \\
\hline Logarithm & 0.38 & 51.35 & 1 & 84 & 0.00 & 5.378 & 7.792 & $y=7.792 \ln (x)+5.378$ \\
\hline Power & 0.46 & 72.60 & 1 & 84 & 0.00 & 1.492 & 1.340 & $y=1.492 x^{1.340}$ \\
\hline Exponential & 0.37 & 49.51 & 1 & 84 & 0.00 & 1.057 & 0.461 & $y=1.057 e^{0.461 x}$ \\
\hline
\end{tabular}

TABLE 5: Changing trends of broadleaf forest, needleleaf forest, croplands, and grasslands (with the square of correlation coefficient $\left(R^{2}\right)$, significance level (Sig.), and regression models).

\begin{tabular}{lccc}
\hline Type & Regression model & $R^{2}$ & Sig. \\
\hline Broadleaf forest & $y=0.2348 x+1.9174$ & 0.24 & $0.019^{* *}$ \\
Needleleaf forest & $y=0.1305 x+2.0052$ & 0.25 & $0.002^{* * *}$ \\
Croplands & $y=-0.3083 x+1.192$ & 0.49 & $0.064^{*}$ \\
Grasslands & $y=0.4479 x-2.0488$ & 0.26 & $0.055^{*}$ \\
\hline
\end{tabular}

Notes. ${ }^{* * *}$ Significant at $1 \%$ level, ${ }^{* *}$ significant at $5 \%$ level, and ${ }^{*}$ significant at $10 \%$ level.

the whole, suggesting that the canopy heights of broadleaf forest, needleleaf forest, and grasslands all will increase with LAI. And the $R^{2}$ of broadleaf forest, needleleaf forest, and grasslands are $0.24,0.25$, and 0.26 . They are significant at the $10 \%$ significance level. There is a negative correlation between the changing trend of $H$ and LAI of cropland, which is contrary to that of their land cover types and inconsistent with the common sense; it may be due to the following reasons. First, the data of croplands is greatly influenced by the types of the crop. Second, the analyzed result is not significant correlation between $\mathrm{H}$ and LAI since there is very limited data of this land cover type in the dataset used in this study.

By contrast, the results well reflected the correlation between $H$ and LAI in the other three land cover types. The result indicated that there is a positive correlation between $H$ and LAI on the whole, and the change of LAI has some influence on the change of the vegetation height; that is, the larger the LAI is, the higher the vegetation height will be, and vice versa. Besides, there is some variation in the degree of correlation between $H$ and LAI in different land cover types.

\section{Conclusions}

The results show that there is significant positive correlation between $H$ and LAI, and the power function relationship between $H$ and LAI is especially significant. Besides, this study also analyzed the relationship between $H$ and LAI with the vegetation type of broadleaf forest, needleleaf forest, croplands, and grasslands. The result indicates that there is significant difference in relationship between $H$ and LAI among different land cover types. Specifically, there is a significantly positive relationship between $H$ and LAI of broadleaf forest, needleleaf forest, and grasslands, while there is negative correlation between $H$ and LAI of croplands. In addition, the instrument used to measure LAI in different sites is not exactly the same, which increases the uncertainties in the relationship between LAI and $H$.

More types of vegetation dataset should be included to improve the robustness of this study. At the same time, for the data shortage, this study only analyzed the relationship between $H$ and LAI of broadleaf forest, needleleaf forest, grasslands, and some other vegetation cover type, so the future studies should analyze a comprehensive relationship between $H$ and LAI and include a wider range of vegetation cover types to quantify the role of vegetation on heat transport.

\section{Conflict of Interests}

The authors declare that there is no conflict of interests regarding the publication of this paper.

\section{Acknowledgments}

This research was supported by the Project of the National Natural Science Foundation of China (Grant no. 41071343) and the National Key Programme for Developing Basic Science of China (Grant no. 2010CB950900).

\section{References}

[1] R. R. Nemani, S. W. Running, R. A. Pielke, and T. N. Chase, "Global vegetation cover changes from coarse resolution satellite data," Journal of Geophysical Research D, vol. 101, no. 3, pp. 7157-7162, 1996.

[2] R. Darvishzadeh, A. Skidmore, M. Schlerf, and C. Atzberger, "Inversion of a radiative transfer model for estimating vegetation LAI and chlorophyll in a heterogeneous grassland," Remote Sensing of Environment, vol. 112, no. 5, pp. 2592-2604, 2008.

[3] H. G. Takahashi, T. Yoshikane, M. Hara, K. Takata, and T. Yasunari, "High-resolution modelling of the potential impact of land surface conditions on regional climate over Indochina associated with the diurnal precipitation cycle," International Journal of Climatology, vol. 30, no. 13, pp. 2004-2020, 2010.

[4] D. J. Selkowitz, G. Green, B. Peterson, and B. Wylie, "A multisensor lidar, multi-spectral and multi-angular approach for mapping canopy height in boreal forest regions," Remote Sensing of Environment, vol. 121, pp. 458-471, 2012.

[5] J. M. Chen and T. A. Black, "Measuring leaf area index of plant canopies with branch architecture," Agricultural and Forest Meteorology, vol. 57, no. 1-3, pp. 1-12, 1991.

[6] B. Wu, Y. Zeng, and J. Huang, "Overview of LAI/FPAR retrieval from remotely sensed data," Advance in Earth Sciences, vol. 10, no. 4, pp. 585-590, 2004. 
[7] G. B. Bonan, "Importance of leaf area index and forest type when estimating photosynthesis in boreal forests," Remote Sensing of Environment, vol. 43, no. 3, pp. 303-314, 1993.

[8] J. L. R. Jensen, K. S. Humes, L. A. Vierling, and A. T. Hudak, "Discrete return lidar-based prediction of leaf area index in two conifer forests," Remote Sensing of Environment, vol. 112, no. 10, pp. 3947-3957, 2008.

[9] M. R. Raupach, "Simplified expressions for vegetation roughness length and zero-plane displacement as functions of canopy height and area index," Boundary-Layer Meteorology, vol. 71, no. 1-2, pp. 211-216, 1994.

[10] J. C. Kaimal and J. J. Finnigan, Atmospheric Boundary Layer Flows: Their Structure and Measurement, Oxford University Press, New York, NY, USA, 1994.

[11] A. R. Desai, A. Noormets, P. V. Bolstad et al., "Influence of vegetation and seasonal forcing on carbon dioxide fluxes across the Upper Midwest, USA: implications for regional scaling," Agricultural and Forest Meteorology, vol. 148, no. 2, pp. 288-308, 2008.

[12] G. Patenaude, R. Milne, and T. P. Dawson, "Synthesis of remote sensing approaches for forest carbon estimation: reporting to the Kyoto Protocol," Environmental Science and Policy, vol. 8, no. 2, pp. 161-178, 2005.

[13] H. Andersen, S. E. Reutebuch, and R. J. McGaughey, "A rigorous assessment of tree height measurements obtained using airborne lidar and conventional field methods," Canadian Journal of Remote Sensing, vol. 32, no. 5, pp. 355-366, 2006.

[14] W. G. M. Bastiaanssen, M. Menenti, R. A. Feddes, and A. A. M. Holtslag, "A remote sensing surface energy balance algorithm for land (SEBAL): 1. Formulation," Journal of Hydrology, vol. 212-213, pp. 198-212, 1998.

[15] R. G. Allen, M. Tasumi, and R. Trezza, "Satellite-based energy balance for mapping evapotranspiration with internalized calibration (METRIC) - model," Journal of Irrigation and Drainage Engineering, vol. 133, no. 4, pp. 380-394, 2007.

[16] I. R. Cowan, "Mass, heat and momentum exchange between stands of plants and their atmospheric environment," Quarterly Journal of the Royal Meteorological Society, vol. 94, no. 402, pp. 523-544, 1968.

[17] C. B. Tanner and W. L. Pelton, "Potential evapotranspiration estimates by the approximate energy balance method of Penman," Journal of Geophysical Research, vol. 65, no. 10, pp. 33913413, 1960.

[18] Ü. Rannik, T. Markkanen, J. Raittila, P. Hari, and T. Vesala, “Turbulence statistics inside and over forest: influence on footprint prediction," Boundary-Layer Meteorology, vol. 109, no. 2, pp. 163-189, 2003.

[19] A. J. Pitman, "Assessing the sensitivity of a land-surface scheme to the parameter values using a single column model," Journal of Climate, vol. 7, no. 12, pp. 1856-1869, 1994.

[20] A. Verhoef, K. G. McNaughton, and A. F. G. Jacobs, "A parameterization of momentum roughness length and displacement height for a wide range of canopy densities," Hydrology and Earth System Sciences, vol. 1, no. 1, pp. 81-91, 1997.

[21] T. Nakai, A. Sumida, K. Daikoku et al., "Parameterisation of aerodynamic roughness over boreal, cool- and warm-temperate forests," Agricultural and Forest Meteorology, vol. 148, no. 12, pp. 1916-1925, 2008.

[22] D. Y. Hollinger, S. V. Ollingerw, A. D. Richardsonw et al., "Albedo estimates for land surface models and support for a new paradigm based on foliage nitrogen concentration," Global Change Biology, vol. 16, no. 2, pp. 696-710, 2010.
[23] J. Anderson, M. E. Martin, M. Smith et al., "The use of waveform lidar to measure northern temperate mixed conifer and deciduous forest structure in New Hampshire," Remote Sensing of Environment, vol. 105, no. 3, pp. 248-261, 2006.

[24] D. S. Kimes, K. J. Ranson, G. Sun, and J. B. Blair, "Predicting lidar measured forest vertical structure from multi-angle spectral data," Remote Sensing of Environment, vol. 100, no. 4, pp. 503-511, 2006.

[25] M. A. Lefsky, W. B. Cohen, G. G. Parker, and D. J. Harding, "Lidar remote sensing for ecosystem studies: lidar, an emerging remote sensing technology that directly measures the threedimensional distribution of plant canopies, can accurately estimate vegetation structural attributes and should be of particular interest to forest, landscape, and global ecologists," Bioscience, vol. 52, no. 1, pp. 19-30, 2002.

[26] M. Chopping, G. G. Moisen, L. Su et al., "Large area mapping of southwestern forest crown cover, canopy height, and biomass using the NASA Multiangle Imaging Spectro-Radiometer," Remote Sensing of Environment, vol. 112, no. 5, pp. 2051-2063, 2008.

[27] M. Hayashi, N. Saigusa, H. Oguma, and Y. Yamagata, "Forest canopy height estimation using ICESat/GLAS data and error factor analysis in Hokkaido, Japan," ISPRS Journal of Photogrammetry and Remote Sensing, vol. 81, pp. 12-18, 2013.

[28] J. A. Gamon, C. B. Field, M. L. Goulden et al., "Relationships between NDVI, canopy structure, and photosynthesis in three Californian vegetation types," Ecological Applications, vol. 5, no. 1, pp. 28-41, 1995.

[29] S. Gao, Z. Niu, N. Huang, and X. Hou, "Estimating the leaf area index, height and biomass of maize using HJ-1 and RADARSAT-2," International Journal of Applied Earth Observation and Geoinformation, vol. 24, pp. 1-8, 2013.

[30] G. Asrar, R. B. Myneni, and B. J. Choudhury, "Spatial heterogeneity in vegetation canopies and remote sensing of absorbed photosynthetically active radiation: a modeling study," Remote Sensing of Environment, vol. 41, no. 2-3, pp. 85-103, 1992.

[31] D. Baldocchi, E. Falge, L. Gu et al., "FLUXNET: a new tool to study the temporal and spatial variability of ecosystem-scale carbon dioxide, water vapor, and energy flux densities," Bulletin of the American Meteorological Society, vol. 82, no. 11, pp. 24152434, 2001.

[32] B. L. Turner II, D. Skole, S. Sanderson, G. Fischer, L. O. Fresco, and R. Leemans, "Land-use and land-cover change: science/ research plan," HDP Report7/IGBP Report 35, 1995.

[33] W. B. Cohen, T. K. Maiersperger, Z. Yang et al., "Comparisons of land cover and LAI estimates derived from ETM+ and MODIS for four sites in North America: a quality assessment of 2000/2001 provisional MODIS products," Remote Sensing of Environment, vol. 88, no. 3, pp. 233-255, 2003.

[34] J. Cho, S. Miyazaki, P. J. F. Yeh, W. Kim, S. Kanae, and T. Oki, "Testing the hypothesis on the relationship between aerodynamic roughness length and albedo using vegetation structure parameters," International Journal of Biometeorology, vol. 56, no. 2, pp. 411-418, 2012. 

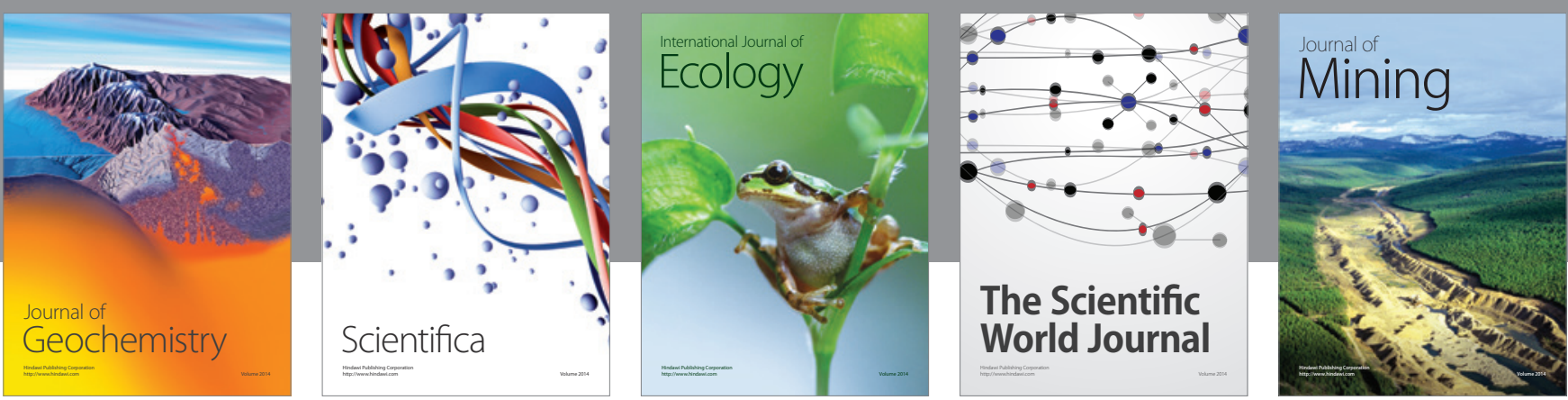

The Scientific World Journal
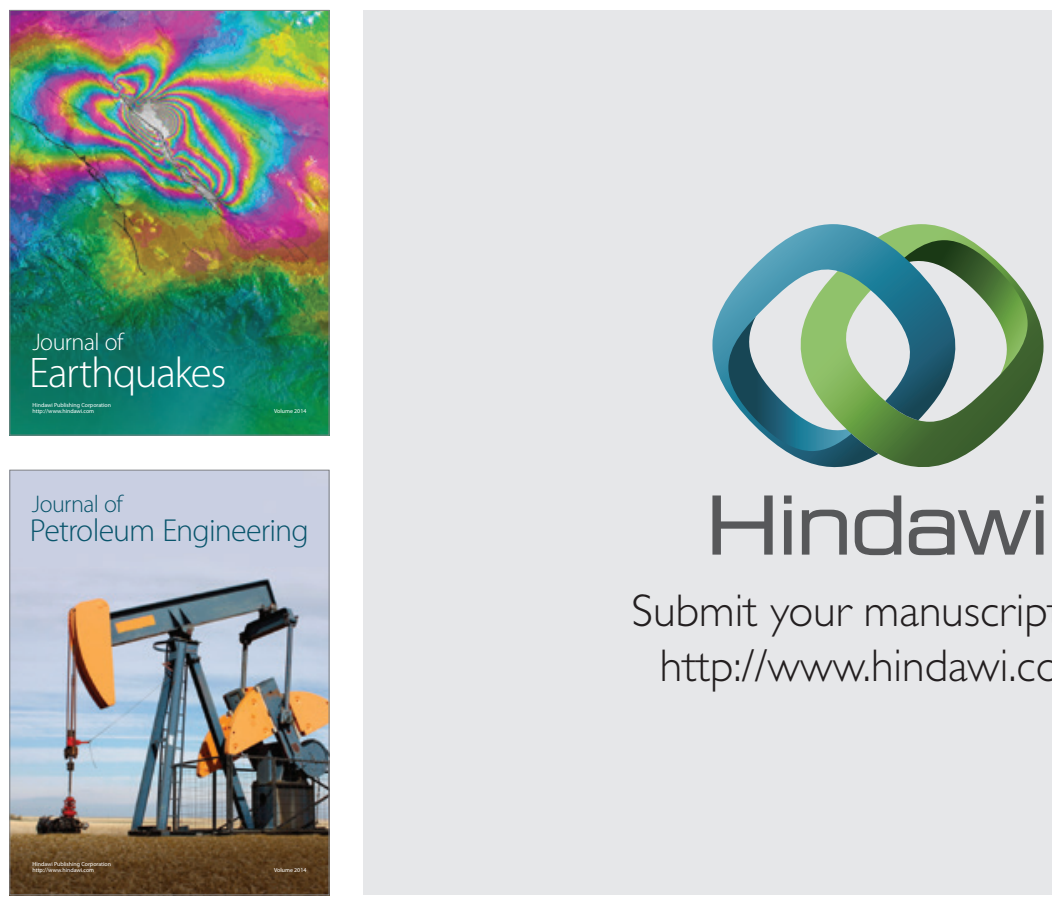

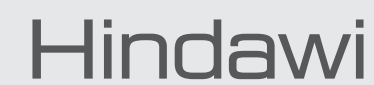

Submit your manuscripts at

http://www.hindawi.com
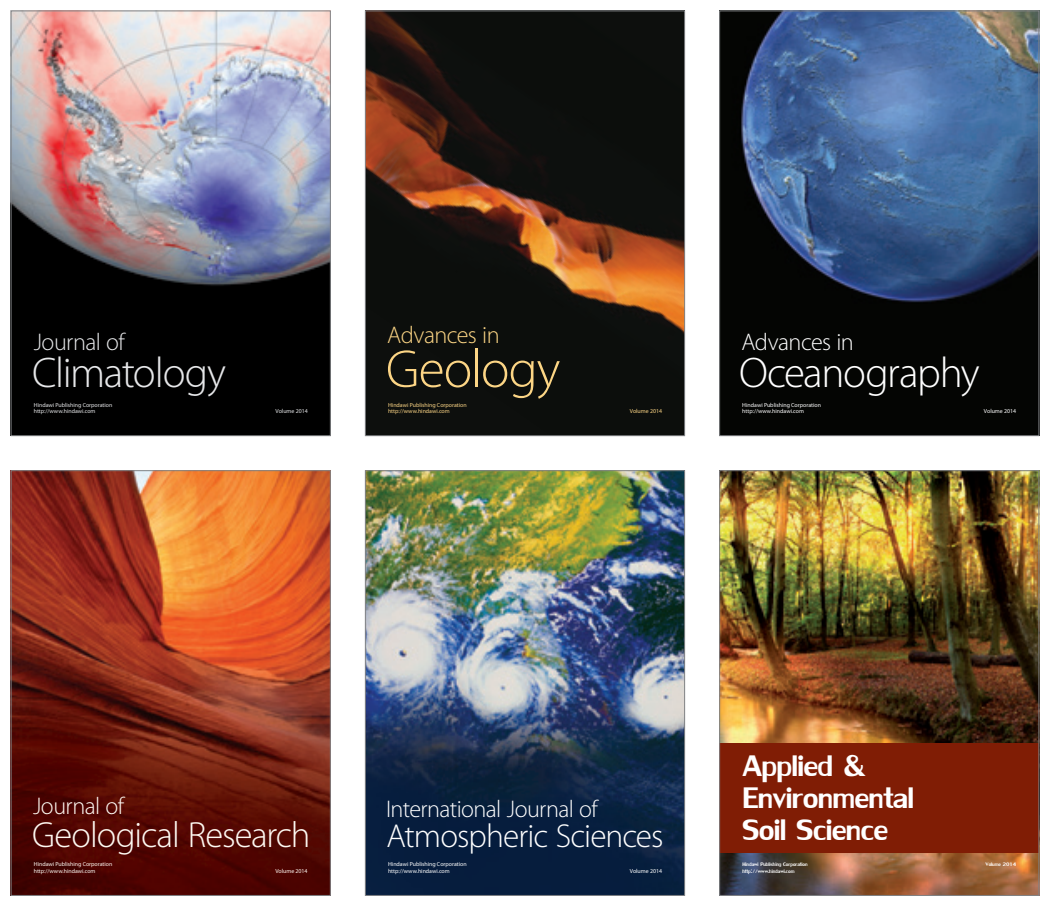
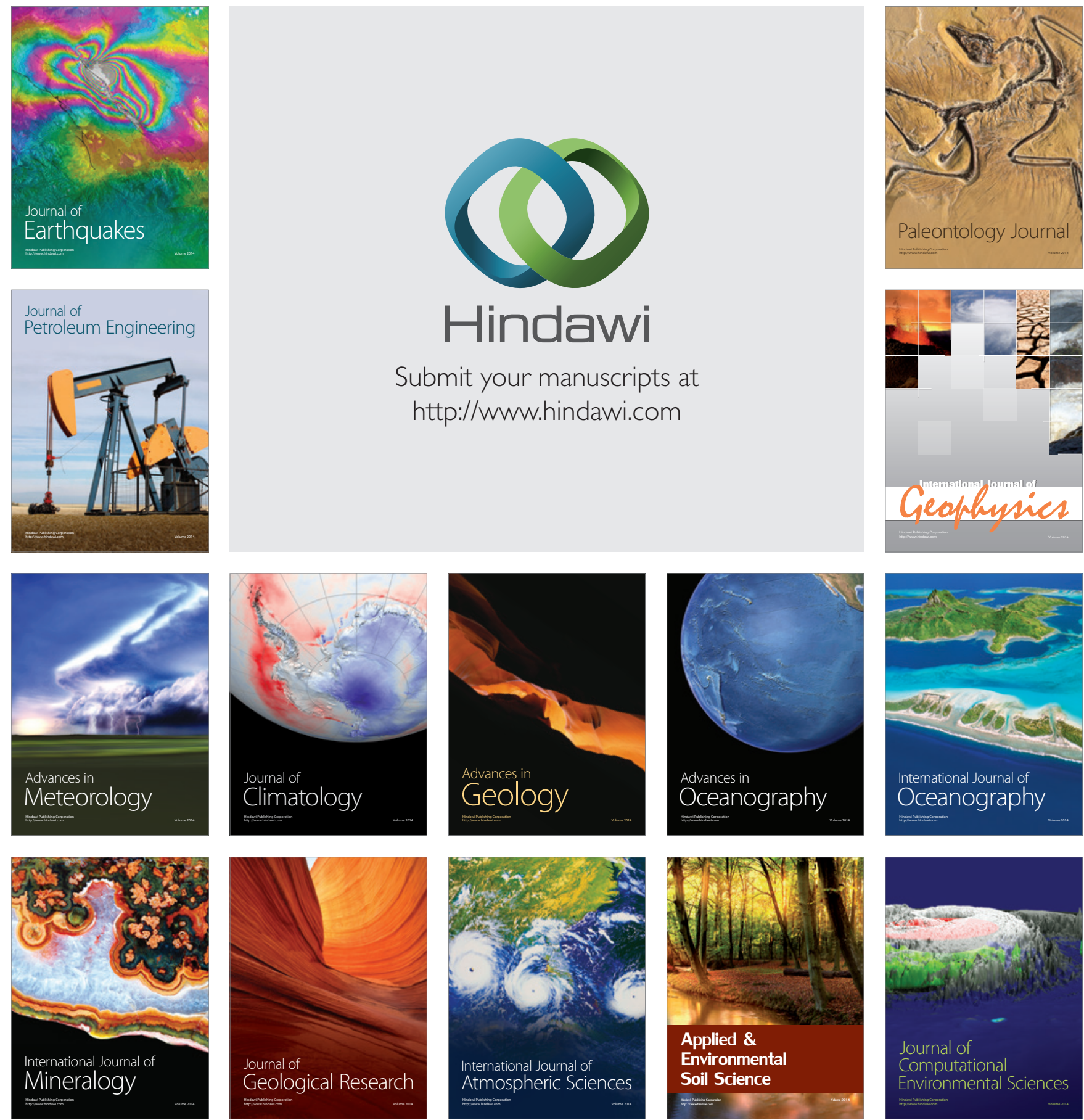